\title{
NEGRO Y FEMENINO. LA NOVELA CRIMINAL ESCRITA POR MUJERES ${ }^{1}$
}

En los últimos años hemos asistido a un auge sin igual de la narrativa criminal $^{2}$ tanto en el ámbito literario como en el fílmico. ${ }^{3}$ A las intrigas históricas con templario indispensable y fondo de María Magdalena, les han sucedido como fenómeno de cultura popular los bestsellers de la novela criminal nórdica y se ha producido una revitalización muy amplia del viejo género que comenzó con Edgar Allan Poe y que siempre se ha resistido a su confinamiento en un paradigma estricto y único o a su aparente destino de paraliteratura, de producto de quiosco.

La narrativa criminal, como tantos otros fenómenos culturales, empezó tarde en la Península Ibérica. En el siglo XIX sus características de literatura urbana para un público de clase media casaban mal con una sociedad rural que, en cuestión de crímenes, seguía anclada en los romances de ciego y en los folletines sangrientos. El franquismo empeoró la situación, porque, como han afirmado muchos críticos, entre ellos José Colmeiro, ${ }^{4}$ la "nueva España" no podía tolerar la perturbación social y mental que un crimen representa, ni sería posible en ese contexto político crear una figura literaria positiva y verosímil de policía como la que representaba el comisario Maigret de Simenon. Por eso el género quedó

\footnotetext{
${ }^{1}$ Este dossier forma parte de los resultados del proyecto "Mujeres y novela criminal en España (1975-2010): autoras, figuras de poder, víctimas y criminales. (MUNCE) FEM2011-22870” y del Grup de Recerca Consolidat "GRC Creació i pensament de les dones (2014 SGR 44)”.

${ }^{2}$ Utilizamos este término, procedente de la crítica anglosajona, en lugar del más tradicional "narrativa policiaca" porque no todos estos textos tienen un detective o un policía como protagonista, pero todos contienen, en algún momento, un crimen o un delito y su investigación. Por otra parte, "novela negra" define de forma adecuada sólo una parte de este corpus narrativo.

${ }^{3}$ Es especialmente notable el auge del género criminal en series de televisión, tanto las procedentes de los Estados Unidos, como las realizadas en España y en otros países europeos.

${ }^{4}$ Ver José F. Colmeiro (1994), La novela policíaca española. Teoría e historia crítica (Barcelona, Anthropos).
} 
confinado durante esos años a colecciones de novela popular donde el mal sucedía siempre "fuera" y los autores se ocultaban bajo un seudónimo en inglés o bien a textos y a personajes más cercanos al costumbrismo que a la narrativa criminal, como el Plinio de García Pavón.

La Transición lo fue también para el género criminal. Es imprescindible recordar la serie Carvalho, de Vázquez Montalbán, que, a modo de nuevos Episodios Nacionales, trazó la crónica, casi año a año, de la llegada de la democracia y también de su desencanto.

Ese es también el contexto histórico en el que, en 1979, Lourdes Ortiz publicó Picadura mortal iniciando con esta novela un nuevo camino, el de la narrativa criminal de autoría femenina. Aunque, como en tantos otros campos, Emilia Pardo Bazán fue pionera con La gota de sangre (1911) y en los años treinta del siglo XX se publicaron algunos títulos de "novela de enigma", como Crim (1936) de Mercè Rodoreda, la aparición de un número significativo de textos de narrativa criminal escrita por mujeres en España —en todos sus subgéneros, ya no solo novela de misterio, o de enigma, sino también novela negra propiamente dicha o de procedimiento policial o jurídico- se produce, por las razones de índole política y cultural ya mencionadas, a partir de 1975 y crece durante los años noventa y la primera década del siglo XXI hasta convertirse hoy en una realidad indiscutible. Uno de los resultados de nuestro proyecto de investigación Mujeres y novela criminal en España (1975-2010): autoras, figuras de poder, víctimas y criminales. (MUNCE) FEM2011-22870 ha sido la publicación en acceso libre de una web-base de datos (www.ub.edu/munce) que tiene, entre otras funciones, la de ser un catálogo de esta producción, que no es escasa ni meramente testimonial, sino que constituye un corpus amplio, complejo y en constante crecimiento, formado, en el momento de la redacción de este texto, por 137 textos y 65 autoras.

La novela criminal $-y$ su autoría femenina- ya no puede, pues, considerarse algo marginal, sino una forma narrativa en torno a la cual se articula una buena parte de la literatura popular. La "fórmula criminal" se ha vuelto fronteriza con otros géneros: novela de terror, novela urbana, novela política, etc. Por otra parte, la tradicional hegemonía anglosajona ha sido sustituida por la avalancha de autores escandinavos, donde no es oro todo lo que reluce, con sus crímenes crueles y gélidos cuyos efectos sobre el género en el resto de Europa están aún por ver. Y en este boom actual encontramos en nuestro contexto muchos nombres de mujer, como ya había sucedido en la literatura británica y americana, donde Sue Grafton o Sara Paretsky, herederas de la ya canónica Patricia Highsmith, son figuras consagradas. Obviamente, las escritoras de narrativa criminal no constituyen un bloque homogéneo, no todas escriben desde la conciencia feminista, no usan la misma matriz literaria, no se sitúan en la misma perspectiva social, y tampoco los resultados obtenidos alcanzan el 
mismo nivel literario, pero entre todas crean un tejido de textura diversa que contribuye a la visibilización de la escritura femenina.

A modo de resumen necesariamente incompleto recordemos cómo, a la novela ya mencionada de Lourdes Ortiz, ${ }^{5}$ le siguieron las pioneras de los años ochenta: Marina Mayoral, Núria Mínguez, Josefa Contijoch, Maria Aurèlia Capmany y Maria-Antònia Oliver, entre otras. Tras ellas llegó el hito fundamental que significó en los noventa la serie creada por Alicia Giménez Bartlett con la inspectora Petra Delicado, que representaba un nuevo empoderamiento femenino. Ya en el siglo XXI, se les han sumado nombres como Berna González Harbour, Blanca Álvarez, Marta Sanz, Mercedes Castro, Rosa Ribas, Cristina Fallarás, Empar Fernández o Dolores Redondo. Un abanico que abarca posiciones estéticas y voluntades literarias de todo tipo ${ }^{6}$ y también todo el arco ideológico, desde la novela criminal lesbiana de Isabel Franc y Susana Hernández al curioso caso de novela criminal católica que encarna Reyes Calderón.

Por otra parte, la novela criminal de autoría femenina se ha extendido a todas las lenguas y culturas del estado de forma proporcional y coherente con sus respectivas situaciones sociolingüísticas y con la composición de su público potencial. Es notable la producción en catalán, donde habría que destacar a Teresa Solana, que en Negres tempestes une de forma muy interesante el retrato irónico de la Barcelona de hoy con la memoria histórica, la reciente aportación de Carolina Solé, que en Ulls de gel ha demostrado que también hay crímenes en el mundo rural, la incursión en el género de una figura consagrada como Carme Riera con Natura quasi morta, la reaparición, después de muchos años alejada del género, de Margarida Aritzeta o el reciente debut de Anna Maria Villalonga. Desde el país vasco francés, Itxaro Borda crea una detective rural -Amaia Ezpeldoi- que lo mismo investiga una muerte misteriosa que el robo de una vaca o la desaparición de unos asistentes a un congreso de onomástica en Bilbao. Y en Galicia Laura Caveiro nos ha ofrecido una deliciosa parodia de los paradigmas de la novela negra norteamericana, Polas inmensas e alleas fortunas.

\footnotetext{
${ }^{5}$ Lourdes Ortiz no ha vuelto a escribir novela criminal. De todos los títulos recogidos en nuestra web-base de datos sólo 44 forman parte de alguna serie, el resto son obras aisladas. El fenómeno de la "novela única" es muy frecuente entre las autoras - cosa contraria a la tradición del género literario, que se alimenta de la fidelización del lector a su personaje central, desde Sherlock Holmes a Pepe Carvalho- y puede ser interpretado de diversas formas, como un ejercicio de estilo - caso de Carme Riera, que ha afirmado no querer repetir la experiencia- o como una manifestación del recelo de las escritoras a quedar marcadas con la etiqueta de una literatura que la crítica literaria ha contemplado hasta hoy -aunque lentamente las cosas están cambiando- de forma displicente cuando no despreciativa.

${ }^{6}$ Hay que destacar aquí la expresa voluntad de literariedad de Marta Sanz, cuyos textos son verdaderos ejercicios de estilo.
} 
La narrativa criminal, y de manera muy específica la escrita por las mujeres, ofrece un testimonio de los cambios sociales en los estereotipos de género. ${ }^{7} \mathrm{El}$ estudio de esta fractura de los estereotipos nos permite construir hipótesis sobre las variaciones en el concepto de las relaciones entre mujer y poder, una evolución que se observa en las tramas e incluso en el lenguaje con que los personajes se expresan y que oscila entre la reproducción y la subversión de los estereotipos de género. Concretemos algunos aspectos relevantes de estos cambios. El primero de ellos sería la representación de figuras de poder femeninas, mujeres empoderadas y con agencia. Estas nuevas investigadoras practican sin conflictos éticos relevantes lo que Amelia Valcárcel llamó "el mal del amo", es decir, participan de la misma estructura del poder patriarcal: son mujeres policías (Petra Delicado, de Alicia Giménez Bartlett; María Ruiz, de Berna González Harbour; Cornelia Weber-Tejedor, de Rosa Ribas; Amaia Salazar, de Dolores Redondo; Norma Forester, de Teresa Solana; Mina Fuster, de Margarida Aritzeta, etc.) o juezas (Gabriela Aldama, de Elisa Beni o Lola MacHor, de Reyes Calderón). Y, al crear esas figuras femeninas, dotadas del "poder del amo" y de su simbología fálica — la ley y la pistola - las autoras han creado también, necesariamente, nuevas masculinidades: hombres subalternos, como el Fermín Garzón de Alicia Giménez Bartlett, hombres víctimas y "hombres frágiles", alterando con ello profundamente las convenciones de la literatura criminal como género literario y también los estereotipos del género sexual.

Las nuevas investigadoras - significativamente policías en su mayoría- son personajes que se relacionan con su entorno de forma muy distinta al solitario detective de la novela negra norteamericana, tienen vínculos sociales, familias, padres a los que cuidar, cuestiones pendientes con la maternidad por resolver y tienen también una conciencia del cuerpo diferente, un cuerpo que ya no puede ser herido solo en las formas tradicionales de la feminidad - el maltrato físico o sexual, por ejemplo- sino también por una bala. En este sentido es especialmente sugerente la relación de la comisaria María Ruiz (Margen de error, de Berna González Harbour) con su cuerpo convaleciente de graves heridas recibidas en cumplimiento de su deber en la novela precedente.

Y, junto a las mujeres empoderadas y a los hombres en transición de modelo, también han aparecido nuevas interpretaciones de crímenes sociales, como el maltrato o la trata de mujeres reflejados en El hombre del corazón negro de Ángela Vallvey, o el retrato de nuevas figuras criminales femeninas: mujeres que asesinan por motivos no sentimentales o de maneras no tradicionalmente ligadas al estereotipo de la feminidad - usando el veneno o induciendo a un hombre a cometer su crimen-, mujeres que participan en grupos de crimen organizado, o

\footnotetext{
${ }^{7}$ El discurso fílmico trabaja paralelamente al discurso narrativo $-\mathrm{y}$ a veces lo precede- en la evolución del paradigma negro-criminal, como vemos en los artículos de París-Huesca y Paszkiewicz.
} 
que asesinan por poder. Y tal vez sea esa reflexión sobre el mal de la mujer el elemento más novedoso - y más perturbador - de estos textos. La violencia de la mujer nos enfrenta a algo que no es normativo y que transgrede tanto los estereotipos patriarcales como el armazón teórico de muchos feminismos, que han tratado de soslayarlo por la incomodidad que suscita y por la facilidad con que puede ser objeto de tergiversación. La mujer criminal ha sido tratada por la criminología clásica de origen lombrosiano como un monstruo o como una víctima, en cualquier caso como un ser sin agencia, aunque sea agencia para el mal. Pero la "catástrofe simbólica", en palabras de Adriana Cavarero, ${ }^{8}$ que significó el caso de las torturadoras de Abu Ghraib ha mostrado la necesidad de este tipo de análisis.

El dossier que presentamos ofrece un mosaico de aproximaciones a estas cuestiones. El artículo de José Colmeiro - "Novela policiaca, novela política"aparece en primer lugar tanto por la relevancia de su autor, cuya tesis ya mencionada fue pionera en los estudios sobre el género criminal en el ámbito hispánico, como por sus características de texto introductorio al género literario y a su historia en España.

Los siguientes son tres artículos centrados en aspectos concretos de la obra de algunas de estas autoras. Stewart King, que es también uno de los estudiosos de largo recorrido del género criminal, incide en la recuperación de algunos aspectos de la "novela de enigma" - y no siempre como parodia- en las obras de una de las voces más representativas del género en catalán, Teresa Solana. Laia Manonelles nos ofrece una aproximación interdisciplinar, desde su perspectiva de historiadora del arte, a la figura de una de las arquetípicas "malas mujeres" de la historia contemporánea, Enriqueta Martí, "la vampira de la calle Ponent", a través de la relectura del mito que Elsa Plaza hizo en su novela El cielo bajo los pies. Melissa Culver, de forma especialmente sugerente, analiza en los textos de Dolores Redondo y de Carolina Solé la importancia de la subjetividad de las investigadoras para la resolución del crimen frente al neopositivismo generado por el modelo CSI.

Finalmente, los dos últimos artículos plantean cuestiones sobre textos fílmicos. El texto de Eva París-Huesca vuelve a un clásico de la filmografía española y a una de sus pioneras, Pilar Miró, para analizar los desafíos a la convención del estereotipo de la femme fatale que planteó la directora en Beltenebros y que contribuyeron a desestabilizar los férreos roles de género del cine negro. Cierra el dossier, en diálogo fructífero con el anterior, el artículo de Katarzyna Paszkiewicz, que parte de las convenciones del cine negro para estudiar su disolución en Mataharis, de Icíar Bollaín, donde las protagonistas se

\footnotetext{
${ }^{8}$ Adriana Cavarero (2009), Horrorismo. Nombrando la violencia contemporánea, Saleta de Salvador Agra (trad.), Anthropos, Universidad Autónoma Metropolitana, Barcelona, México D.F., p. 180.
} 
adueñan de la mirada y sacan a la luz las paradojas de la representación de la mujer como figura de poder en la ficción criminal.

Seis trabajos, pues, que en sus diferencias y en sus complementariedades nos permiten visibilizar distintos aspectos de una producción, la de narrativa criminal de autoría femenina, que dista mucho de ser testimonial y que aporta elementos de análisis y reflexión social y artística de máxima actualidad.

ELENA LOSADA SOLER Universitat de Barcelona 